\title{
SYNTHESIS
}

Synthesis, vol. 26, nº 1, e054, junio-noviembre 2019. ISSN 1851-779X

Universidad Nacional de La Plata.

Facultad de Humanidades y Ciencias de la Educación.

Centro de Estudios Helénicos

\section{Tapiz y cifrado: tradición clásica en tres cuentos de Jullio Cortázar (1951-1956)}

\section{Tapestry and Score: Classical Tradition in Julio Cortázar's Three Short Stories (1951-1956)}

Daniela Evangelina Chazarreta*

Universidad Nacional de La Plata - CONICET, Argentina

dchazarreta@fahce.unlp.edu.ar

(iD http://orcid.org/0000-0003-1211-5879

\section{Resumen:}

En este artículo indagamos las significaciones de la tradición clásica en "Circe”, "Las ménades” y "El ídolo de las Cícladas" de Julio Cortázar, teniendo como hipótesis general que este sustrato (la tradición clásica) le permite al escritor argentino esgrimir dos estrategias: por una parte, la tradición clásica representa una cita de autoridad que habilita el ingreso del orbe de la alta cultura a su estética y, por otra parte, la tradición clásica le permite inscribir el pensamiento mágico y mítico tan apreciado en su modo de ver el arte y el mundo, perspectiva en la que la experiencia latinoamericana tiene un sitio particular. Para arribar a estos resultados iniciamos, en primer lugar, con una presentación del marco teórico vinculado a la categoría de tradición clásica. En segundo lugar, nos dedicaremos a analizar los cuentos mencionados.

Palabras Clave: Julio Cortázar, Tradición clásica, Cuentística.

\begin{abstract}
:
In this paper, we consider the classical tradition significance in Julio Cortázar's "Circe”, "Las ménades" and "El ídolo de las Cícladas". The hypothesis is that the classical tradition appears with two important stamps: firstly, the classical tradition is an authority quote that allows the entry of high culture in Cortázar's aesthetics; secondly, this tradition is connected with magic and mythic thought so valued in the poetry and world view of this writer, in which the Latin American experience and history has a particular place. To arrive to these results, we begin with the theoretical framework beyond the classical tradition category and we continue with the short-stories analysis.
\end{abstract}

KEYWORDS: Classical Tradition, Julio Cortázar, Short Story.

Ahora es más difícil hablar de esto, está mezclado con otras historias que uno agrega a base de olvidos menores, de falsedades mínimas que tejen y tejen por detrás de los recuerdos...

(Cortázar, "Circe")

Estas palabras ciñen una parte del presente artículo en el que indagamos las significaciones que tiene la tradición clásica en "Circe", "Las ménades" y "El ídolo de las Cícladas", ${ }^{1}$ teniendo como hipótesis general que este sustrato (la tradición clásica) le permite a Cortázar esgrimir dos estrategias: por una parte, la tradición clásica representa una cita de autoridad que habilita el ingreso del orbe de la alta cultura a su estética y, por otra parte, la tradición clásica le permite inscribir el pensamiento mágico y mítico tan apreciado en su modo de ver el arte y el mundo, perspectiva en la que la experiencia latinoamericana tiene un sitio particular. Para a rribar a estos resultados iniciamos, en primer lugar, con una presentación del marco teórico vinculado a la categoría de tradición clásica. En segundo lugar, nos dedicaremos a analizar los cuentos mencionados.

\section{BREVE CODA SOBRE EL MARCO TEÓRICO}

Como se sabe, la problemática noción de tradición ha realizado un periplo de largo aliento en la historia de la cultura hispanoamericana, sobre todo en la literatura que es la que nos compete específicamente en este artículo. Tanto Rubén Darío como Jorge Luis Borges y José Lezama Lima, por ejemplo, han legitimado la capacidad hispanoamericana de incorporar toda la cultura occidental sin temores, prejuicios ni dilaciones. ${ }^{2}$ 
Este apartado tiene el objetivo de presentar sintéticamente por qué damos preferencia a la categoría de tradición clásica en lugar de otros modos de denominar los matices que la apropiación del universo grecolatino tiene en la cultura hispanoamericana.

En primer lugar, es importante tener presente que la reflexión acerca del problema de la tradición y sus implicancias ha tenido lugar en nuestras letras con el fin de dirimir y dar cauce a diversas operaciones de apropiación, conformación y búsqueda de una autonomía literaria. Desde este contexto la tradición es, entonces, un proceso activo que se construye desde el presente tras la lectura y edificación del pasado que implica operaciones de selección. En segundo lugar, también es relevante considerar que tomamos distancia de lo que se ha considerado como tradición clásica en The Classical Tradition de Gilbert Highet (1949) o en La función del mito clásico en la literatura contemporánea (1957) de Luis Díez del Corral, en los cuales la noción que prevalece es la de que el presente se limita a imitar un pasado cuyo ideal de perfección es el universo grecolatino. Finalmente, es importante subrayar que si pensamos la categoría de tradición desde cómo se problematizó en el seno de la literatura hispanoamericana y no damos cauce a la noción que proverbialmente la ha definido solo como una continuidad y recuperación de ciertos estilos y cosmovisiones, entonces, las significaciones de la tradición clásica en la literatura hispanoamericana emergen con una riqueza inusitada.

Desde la problemática de nuestra propia literatura la tradición es un hecho insoslayable e innegable; la habilidad del escritor está, entonces, en asumir posesiones simbólicas (estéticas, intelectuales) del corpus que ha heredado sorteando las nociones de centro y epígono para focalizarse en el contexto de producción propio del hecho artístico hispanoamericano (Lezama Lima, 1941), obliterando o sorteando, a partir de diversas estrategias, la extensa e histórica trayectoria de la civilización europea como única condición de prestigio y autoridad en desmedro de las culturas emergentes.

\section{LA TRADición CLÁSiCA SEgúN CoRTÁZAR}

Julio Florencio Cortázar (Bruselas, 1914-París, 1984) publica el ensayo "La urna griega en la poesía de Keats" en el tomo 11 de la Revista de Estudios Clásicos del Instituto de Lenguas y Literaturas Clásicas de la Universidad de Cuyo en 1946. Como se sabe, Bestiario se publica en $1951,{ }^{3}$ es decir, en una fecha muy cercana al ensayo citado sobre Keats. De hecho, muchas de las ideas allí planteadas pueden trasladarse a las significaciones que Cortázar le otorga a la presencia griega clásica en su propia obra (González de Tobia, 1998, p. 90). Nos interesan sobre todo tres concepciones que retomamos en el análisis de los cuentos: apropiación (por la similitud entre la noción considerada por el argentino y la que sostiene Roger Chartier posteriormente), la analogía como una semejanza propiciada por la repetición de condiciones (o "simpatía natural") y la mitología como sistema de referencias mentales. Con este bosquejo vinculado a valoraciones de la tradición clásica retomamos el planteo realizado anteriormente para continuar, luego, con el análisis de los cuentos.

Más allá de una lectura sobre Keats, el ensayo puede interpretarse como un programa estético del propio Cortázar. Para sortear la distancia histórica entre el universo grecolatino y "el mundo moderno" -tal es la denominación de nuestro escritor (2004a, pp. 33)-, Cortázar recurre a la apropiación a través del intuir poético; refiriéndose a John Keats, señala:

El poeta incorpora a su sensibilidad ese aparato científico y estético y extrae de él, junto con un sistema de valores ajenos, la primera conciencia de que tales valores solo históricamente le son ajenos. El camino de apropiación es ahora privativo de su intuir poético; sendero personalísimo de la coexistencia espiritual fuera de tiempo y espacio. (Cortázar, 2004a, p. 42) [Las cursivas son del autor]

La noción de apropiación, aquí utilizada, tiñe el primer modo de aprehensión ligado a lo subjetivo, al universo del sujeto que acomete esa acción. La categoría implica una historia social de usos e interpretaciones prestando atención a las condiciones y procesos que implican las operaciones de construcción de sentido 
y los modos en que se inscriben en las prácticas específicas que los producen (Chartier, 1991, pp. 52-53). Sortear las categorías de tiempo y espacio ("fuera de tiempo y espacio") implica, además, una estrategia, pues la apropiación estaría legitimada por una coincidencia espiritual y estética: la correspondencia, entonces, eludiría las categorías de artistas faro y epígonos o de civilizaciones medulares y culturas emergentes:

Él [Keats] asume esa mitología (...) sin otro fin que el de celebrarla líricamente, como por derecho propio. La asume desde dentro, entera y viviente, a veces como tema, a veces como concitación de poesía en torno a un tema (...). A la noción de mitología como adorno retórico (...) opone Keats una visión del mundo mítico en la que empeña la actitud total de su ser, sin apropiación literaria sino como recobrando un bien propio y natural. (Cortázar, 2004a, pp. 54-55) [A excepción de "recobrando", la cursiva es nuestra]

En el esquema que plantea Cortázar, la apropiación es la operación de incorporación y está enlazada a una operación retórica, la de la analogía, que traduce la cosmovisión en la que el universo es una red de correspondencias; la apropiación, entonces, no es solo un hecho literario ("sin apropiación literaria"), sino cultural o, incluso, antropológico. ${ }^{4}$ Esta noción conduce a la relevancia que adquiere la imagen en la poesía -también sus derivados: metáfora, símil- (Cortázar, 2004b, p. 370), así como la correspondencia entre la naturaleza y el sujeto, lo que denominará "simpatía natural", "proyección sentimental" y "retorno a la naturaleza" (Cortázar, 2004a, p. 61-62):

Poeta puro y simple, y obstinado por eso en defender su bien que no es el de la moral sino el de la Belleza (...) conciencia clarísima de que aun en el orden espiritual puede establecerse una "teoría de correspondencias" y que el creador hace el bien mediante la belleza que de su verso nace (...) poesía pánica, inmersa en realidad sensible y consagrada a su alabanza. (Cortázar, 2004a, p. 98)

La cosmovisión analógica habilita la emergencia de figuras retóricas como la imagen, la metáfora o el símbolo. Las figuras mitológicas son, entonces, un "sistema de referencias mentales" derivadas de la analogía como sistema de aprehensión del mundo:

Para Shelley -como para (...) Valéry- la mitología era ese cómodo sistema de referencias mentales al que puede acudirse con la ventaja de prescindir de explicación al lector medianamente cultivado, cuyas personificaciones se despojan de contingencia temporal para conservar solo sus motivaciones primarias a modo de transparente símbolo. (Cortázar, 2004a, pp. 52-53)

La cosmovisión analógica se enlaza, además, con la concepción de pensamiento mágico y mítico a la que volveremos posteriormente.

\section{"CIRCE"}

Y llegamos a la isla de Eea, donde habita Circe...

(Homero, Odisea 10.135) 5

En la Antigüedad romana, se denominaba bestiario a aquel individuo que cuidaba a las fieras o que luchaba con ellas en el circo; en la Edad Media, se trataba de compendios de animales (reales o fabulosos) que sistematizaban significaciones legendarias con ciertos saberes científicos (García Canclini, 1968, p. 28). Desde su título, Bestiario rescata el universo animal y/o monstruoso ligado a la naturaleza del ser humano. La poesía moderna (incluyendo la hispanoamericana) abunda en ejemplos, pero remitimos solo a uno de ellos: Le Bestiaire ou Cortège d'Orphée (1911) de Guillaume Apollinaire, que seguramente Cortázar conocía recordando, además, el fuerte vínculo entre este intelectual y lo que denominamos poesía moderna. ${ }^{6}$ Los animales ("bestias") están en este primer contario del escritor argentino -e incluso en algunos cuentos de Final del juego- para encarnar la faceta de irracionalidad o, mejor dicho, de todos los aspectos que implican lo contrario a la racionalidad o lógica con que se concibe la civilización de Occidente: "Lo bestial es al mismo tiempo lo que el hombre custodia y contra lo cual combate, y también algo que lo constituye y explica" (García Canclini, 1968, p. 28). 
"Circe", cuento que forma parte del contario, no escapa a estas implicancias. En el relato, el mito griego (que tiene como subtexto el relato homérico) se resemantiza de dos formas: en primer lugar, al insertarse en la realidad porteña de la segunda década del siglo pasado ${ }^{8} \mathrm{y}$, en segundo lugar, porque a partir del epígrafe se incorpora la lectura decadente del mito y con ello una nueva mirada sobre lo femenino ligada a la femme fatale. Esta labor de entramado textual es referida en el cuento; repetimos el epígrafe con que iniciamos este artículo: "Ahora es más difícil hablar de esto, está mezclado con otras historias que uno agrega a base de olvidos menores, de falsedades mínimas que tejen y tejen por detrás de los recuerdos” (Cortázar, 1996a, p. 147). ${ }^{9}$

Rescatamos la noción del relato "mezclado con otras historias" y también la idea de texto como un tejido o entramado. La coexistencia de tramas textuales o palimpsesto contiene dos nudos en el relato cortazariano: el subtexto griego y el intertexto cultural proveniente del imaginario francés finisecular. La referencia al tejido (en la cita anterior) remite, además, al telar de Circe del relato homérico (Odisea 10.23) en una especie de puesta en abismo que envía a la propia construcción (fictio) del texto. Citamos, nuevamente el cuento: "La gente pone tanta inteligencia en esas cosas, y cómo de tantos nudos agregándose nace al final el trozo de tapiz" (Cortázar, 1996a, p.146). ${ }^{10}$

El metadiscurso se enfatiza también en el paralelo entre Mario y el lector, pues ambos deben saber leer los indicios que tienen ante sus ojos: en el caso del personaje del cuento, que peca por racionalizar excesivamente cada evento, debe leer correctamente cada acontecimiento para no terminar muerto como los dos novios anteriores de Delia. En esta línea es muy sugestivo que el apellido de Delia ("Mañara") se identifique sonoramente con "maraña” (Hernández del Castillo, 2005, p 82), es decir, un enredo de hilos o cabellos: ${ }^{11}$ Mario debe aprender a desenredar correctamente la situación para no pasar por lo mismo que los anteriores novios. En el caso del lector, debe reponer los mitemas que, anclados paratextualmente (en el título y en el epígrafe), reescriben el mito de Circe, resemantizándolo.

En la cita del epígrafe de este apartado se manifiesta, también, la definición de mito que se enlaza con la concepción antropológica de la analogía (ligada a la causalidad propia del pensamiento mágico y mítico), pues según Claude Lévi-Strauss ${ }^{12}$ el mito se caracteriza, primeramente, por la repetición que expresa su estructura y por lo tanto exhibe los mitemas y, en segundo lugar, porque el relato mítico no está subordinado a una lógica racional sino que "todo sujeto puede tener cualquier predicado, toda relación concebible es posible" (1961, p. 188).

El nombre de la protagonista del cuento diseña el ingreso de lo maravilloso o fantástico que denominaremos -siguiendo al propio Cortázar- causalidad mágico-mítica: su nombre remite a Delos, espacio mítico por excelencia; su apellido evoca los términos maraña, ya mencionado, y araña aludidos también en el texto ("La madre decía que Delia había jugado con arañas cuando chiquita”, Cortázar, 1996a, p. 145); en el cuento se traza, incluso, la dicotomía entre dos espacios: "Empezaba a creer posible esa doble vida a cuatro cuadras una de otra; la esquina de Rivadavia y Castro Barros era el puente necesario y eficaz” (Cortázar, 1996a, p. 148).

En su ensayo "Para una poética" de 1954, el escritor sigue los postulados presentes en Las funciones mentales en las sociedades inferiores (1910) de Lucien Lévy-Brühl (2004b, 370-371). Eduardo Romano explicita con claridad la asimilación de estos estudios antropológicos en la cosmovisión cortazariana enlazándola a intereses en común con las estéticas modernas de Stephan Mallarmé, T. S. Eliot, Paul Valéry, entre otros, quienes reescribieron los mitos clásicos desde esta nueva perspectiva indagando la conducta humana:

El engarce con las corrientes antropológicas que revalidaban lo mágico, junto con ciertos mitos fundantes, y la apuesta surrealista al inconsciente, sumada a la experimentación que aportaron las vanguardias y que hasta cierto punto pasaba de la poesía a la novela (...), siempre me parecieron mucho más decisivos que sus relaciones con el llamado "fantástico" del siglo XIX. (Romano, 2017, p. 38)

En "Circe" se parodia e hiperboliza el racionalismo a través de los esquemas de lectura o explicación de los hechos que realiza Mario dirigidos por la justificación constante (lo mismo sucederá con el narrador 
de "Las ménades" y con Morand de "El ídolo de las Cícladas"). Esta manera de concebir la sucesión de acontecimientos se denigra continuamente en el relato:

Los Mañara le dijeron a Mario que Delia no había vuelto a sentarse al piano, que se pasaba las horas preparando los licores, los bombones. No lo decían con reproche, pero tampoco estaban contentos; Mario adivinó que los gastos de Delia los afligían. (Cortázar, 1996a, p. 149) [La cursiva es nuestra]

Volviendo al tratamiento mítico, reconocemos los siguientes mitemas que remiten, como indica Ana González de Tobia, "a los ritos sacrificiales que acompañan la imagen mítica conformando con ella una realidad" (1998, p. 93), es decir, reactualizan el mito concibiéndolo como una inflexión atemporal: en primer lugar, el motivo de los alimentos que son utilizados como pócimas; en segundo lugar, el tópico del dominio de los animales; en tercera instancia, Mario (como Odiseo) evade los efectos del hechizo; en cuarto lugar, el vínculo erótico (como parte del rito de dominación de la maga) y, finalmente, la música como uno de los modos de dominación o seducción de parte de Circe. ${ }^{13}$ El texto enfatiza esa repetición presente en el tiempo verbal utilizado y en los complementos temporales:

Cuando estuvo de vuelta vio a Delia en la ventana, mirando la calle vacía por donde antes en noches iguales se iban Rolo y Héctor. Algo de luna se acostaba ya en el piso cerca de Delia, en el plato de alpaca que Delia guardaba en la mano como otra pequeña luna. (Cortázar, 1996a, p. 153) [La cursiva es nuestra]

La repetición también se subraya en el juego de refracción presente en la cita ("como otra pequeña luna").

Delia, entonces, se parangona con Circe a través de las menciones a la magia: "Hizo un gesto como para abrir una puertecita en el aire, un ademán casi mágico" (Cortázar, 1996a, p. 151); y a la alquimia: "Los Mañara la miraban como queriendo leerle la receta, la alquimia minuciosa de quince días de trabajo" (Cortázar, 1996a, p. 148).

La resemantización del mito de Circe involucra, como anticipáramos, el tópico de la femme fatale caro al imaginario europeo de fines del siglo XIX, en especial al decadentismo. El epígrafe del cuento proviene de "The Orchard-Pit", poema incompleto de Dante Gabriel Rossetti (Londres?, 1828-1882), poeta y pintor prerrafaelita. La emergencia de este tópico se debió a cambios sociohistóricos acerca de la consideración de la mujer y a una creciente misoginia debida a su nuevo papel en el trabajo y en la vida pública, el temor a las enfermedades venéreas provocadas por las relaciones extramatrimoniales y de la prostitución, y teorías que avalaban esta misoginia científicamente (Arthur Schopenhauer, Friedrich Nietzsche, Max Nordau, Ezechia Lombroso). ${ }^{14}$ En este contexto, el mito de Circe constituyó un subtexto fructífero de diversas experiencias artísticas, sobre todo la plástica; la maga de Odisea se ligó, por cierto, con la voluptuosidad, la dominación, la naturaleza perversa de la mujer, la ecuación mujer-sexo, causas todas ellas de la depravación sexual y ruina masculinas (según el imaginario hegemónico de la época): todo ello configuraba la advertencia y admonición con respecto al universo femenino (Bornay, 2004, pp. 171-177). ${ }^{15}$

Además del epígrafe, el díptico muerte-sexo vincula a Delia con la femme fatale finisecular. La primera instancia de la dicotomía aparece también en el epígrafe mencionado ("saw the dead white faces that welcomed me in the pit”): la muerte se representa simbólicamente a través de la palidez de Delia y también a través de la luna (Pierrot, 1977, p. 63).

Le ofrecía el bombón como suplicando, pero Mario comprendió el deseo que poblaba su voz, ahora lo abarcaba con una claridad que no venía de la luna, ni siquiera de Delia. (...). Con la mano libre apretó apenas los flancos del bombón pero no lo miraba, tenía los ojos en Delia y la cara de yeso, un pierrot repugnante en la penumbra. (Cortázar, 1996a, p. 154)

La segunda instancia del díptico se vincula también con el mito griego pues Circe solicita a Odiseo que compartan el lecho. En el cuento, Mario obtiene sutiles recompensas amorosas cuando, gracias a su colaboración económica, favorece la preparación de los bombones y licores, brebajes que Delia preparaba minuciosa y perversamente: 
Entonces, pidió a Delia en secreto una lista de las esencias y sustancias necesarias. Ella hizo algo que nunca antes, le pasó los brazos por el cuello y lo besó en la mejilla. Su boca olía despacito a menta. Mario cerró los ojos, llevado por la necesidad de sentir el perfume y el sabor desde debajo de los párpados. Y el beso volvió, más duro y quejándose. (Cortázar, 1996a, p. 149)

El cuento podría leerse como una crítica al modelo de mujer propuesto por la época, diestro en las artes de la cocina, manualidades, etc., pero nos interesa más cómo reaparece el mito. Por una parte, se trata de una referencia culta que traslada, a partir de su apropiación, la cultura grecolatina y, por lo tanto, también su prestigio (belleza dirá Cortázar en el ensayo sobre Keats); por otra parte, el mito se inserta, además, como paradigma o traducción pues, en tanto que su estructura se manifiesta a través de la repetición, permite explicar la presencia de lo maravilloso u ominoso (de la realidad mágico-mítica) en el contexto de lo cotidiano: una hechicera en la urbe porteña de los años 20 del siglo pasado. Si bien existe un anclaje espacial otorgado por una cartografía con diversos puntos y esquinas de Buenos Aires, creemos, sin embargo, que el relato enfatiza lo metadiscursivo, es decir, el ingreso determinado e indefectible de intertextos culturales en el discurso que se está gestando o entramando como el tapiz que Mario intenta recomponer a partir de los maliciosos pero acertados rumores sobre Delia. Así como la esquina Rivadavia y Castro Barros era el pasaje a ese orbe configurado por Delia Mañara, el mito también es el pasaje a otra lógica de pensamiento: uno de los modos más didácticos para traducir esa experiencia de lo real maravilloso.

\title{
"LAS MÉNADES"
}

\author{
¿Y sin embargo verías con placer \\ lo que te ha de ser amargo? \\ Eurípides, Bacantes ${ }^{16}$
}

Las implicancias de la presencia del mito en "Las ménades" sigue algunas de las prescripciones descriptas en torno a "Circe", es decir, el relato mítico se sugiere paratextualmente (a partir del título); se presupone un lector con competencia culta para poder desenhebrar la madeja mítica; los mitemas se enfatizan a partir del recurso retórico de la repetición -sobre todo a nivel léxico-, y se traza el ingreso de lo mítico y mágico a partir de la inflexión espacial reactualizando el repertorio clásico al insertarlo en lo cotidiano:

En realidad yo le tenía un enorme cariño al Maestro, que nos trajo buena música a esta ciudad sin arte, alejada de los grandes centros, donde hace diez años no se pasaba de La Traviata y la obertura de El Guaraní. El Maestro vino a la ciudad contratado por un empresario decidido, y armó esta orquesta que podía considerarse de primera línea. Poco a poco nos fue soltando Brahms, Mahler, los impresionistas, Strauss y Mussorgski. (Cortázar, 1996b, pp. 320-321)

El relato se inserta, de esta manera, en el seno de la dicotomía entre racionalismo y pensamiento mágico y mítico, propio de la estética de Cortázar; la antítesis -llevada al paroxismo en este cuento-, también halla su eco tópico (su marca espacial) a partir de la cual ingresa esta otra causalidad; en dos instancias se hace referencia al bosque ("ese bosque simétrico sin puntos de referencia"), es decir, al espacio agreste en el que se concretaban los rituales báquicos como se relata en Bacantes (vv. 865-870): ${ }^{17}$

Cuando se enderezó, la sala entera estaba de pie y yo con ella, y el espacio era un vidrio instantáneamente trizado por un bosque de lanzas agudísimas, los aplausos y los gritos confundiéndose en una materia insoportablemente grosera y rezumante pero llena a la vez de una cierta grandeza, como una manada de búfalos a la carrera o algo por el estilo. (Cortázar, 1996b, p. 326)

Como en "Casa tomada", la causalidad que irrumpe lo cotidiano y rutinario ingresa desde las imágenes auditivas. Esta impronta se dirime en otra dicotomía antitética, sumamente importante a nivel auditivo, entre el ruido que provocan los espectadores y la melodía de la orquesta, ambos se proyectan a nivel corporal, en los gestos formales y hasta protocolares del Maestro ${ }^{18}$ y en los arrebatos o paroxismos de las mujeres: 
Casi nadie oyó el primer grito porque fue ahogado y corto, pero como la muchacha estaba justamente delante de mí, su convulsión me sorprendió y al mismo tiempo la oí gritar, entre un gran acorde de metales y maderas. Un grito seco y breve como de espasmo amoroso o de histeria. Su cabeza se dobló hacia atrás, sobre esa especie de raro unicornio de bronce que tienen las plateas del Corona, y al mismo tiempo sus pies golpearon furiosamente el suelo mientras las personas a su lado la sujetaban por los brazos. Arriba, en la primera fila de tertulia, oí otro grito, otro golpe en el suelo. (Cortázar, 1996b, p. 325)

El nivel sonoro es sumamente importante porque introduce el mitema del músico y, desde allí, el intertexto ovídico que relata la muerte de Orfeo, "hijo de Apolo" (Metamorfosis XI.9) en manos de las ménades. La melodía armónica (representada por la alta cultura de la música clásica) se opone a los ruidos ${ }^{19}$ de percusión: "a los aplausos se agregaban truenos de zapatos batiendo el piso de las tertulias y palcos"; y a los gritos (Cortázar, 1996b, pp. 324-325).

Ambas instancias son derivaciones señaladas ya por Bacantes de Eurípides y por los estudiosos de los cultos báquicos: ${ }^{20}$

En danzas de coro a lo largo de la noche moveré mi blanco pie celebrando las fiestas báquicas, exponiendo al aire puro, y al rocío, mi cuello, en el gesto ritual. Como la cervatilla que retoza en los verdes placeres del prado, después de escapar a los terrores de la cacería, lejos de la batida, más allá de las redes bien tejidas, mientras el cazador con sus gritos excita el impulso de sus perros. En raudas y esforzadas carreras, en ráfagas, corre por la llanura junto al río, gozosa en la soledad, lejos de los hombres, y por entre los arbustos del bosque de umbrosa melena. (vv. 865-875) ${ }^{21}$

En el tratamiento del mito podemos leer, entonces, dos intertextos: el ovídico y las Bacantes de Eurípides, manifiesto sobre todo por los mitemas propios del ritual dionisíaco (González de Tobia, 1998, p. 95). Uno de los ejes de la resemantización del mito es la repetición de "entusiasmo" (enthusiasmós) presente desde las primeras frases del relato ("como ahora que su entrada estaba provocando un entusiasmo fuera de lo común”). ${ }^{22}$ Otra de las aristas de la reescritura mítica es el descuartizamiento o sparagmós junto con la omofagía o ingestión de la carne cruda sacrificada a la divinidad:

Los gritos sobrepujaban ahora a los aplausos, la gente estaba demasiado ocupada abrazando y palmeando a los músicos para poder aplaudir, de modo que la calidad del estrépito iba virando a un tono cada vez más agudo, roto aquí y allá por verdaderos alaridos entre los que me pareció oír algunos con ese color especialísimo que da el sufrimiento, tanto que me pregunté si en las carreras y en los saltos no habría tipos quebrándose los brazos y las piernas (...). (Cortázar 1996b, p. 328)

Posteriormente se señala: "En el foyer vi algunas mujeres que buscaban espejos y revolvían en sus carteras. Una de ellas debía haberse lastimado porque tenía sangre en el pañuelo" (Cortázar, 1996b, p. 329).

Posteriormente se señala: "En el foyer vi algunas mujeres que buscaban espejos y revolvían en sus carteras. Una de ellas debía haberse lastimado porque tenía sangre en el pañuelo” (Cortázar, 1996b, p. 329).

Finalmente, el mitema de la caza ${ }^{23}$ junto con lo bestial se presenta en los términos analizados en "Circe", en tanto el universo animal traduce la irracionalidad que forma parte del hombre; en el cuento se subraya con insistencia y a partir de símiles esta estampa que comienza como por una vislumbre y que luego predomina en los espectadores (sobre todo en las mujeres): "Las chicas estaban rojas y excitadas, me rodearon como gallinitas cacareantes (hacen pensar en volátiles diversos) para decirme que Mendelssohn había estado bestial" (Cortázar, 1996b, p. 321) [La cursiva es nuestra]. ${ }^{24}$

Los epítetos se suceden a lo largo del cuento (usufructuando oportunamente la disemia): ${ }^{25}$ "carne de gallina", "brutal" (Cortázar, 1996b, p. 322, respectivamente), "bebía soda como un camello"; "una masa negra como moscas en un tarro de dulce"; "daban la impresión de bandadas de cuervos (Cortázar, 1996b, p. 323, respectivamente); "habían convertido a la mayoría de los asistentes en lamentables langostinos sudorosos” (Cortázar, 1996b, p. 324).

El mitema de ver lo prohibido, en este caso, observar los ritos báquicos reservados solo a iniciados (Detienne, 1997, p. 276) también se hace presente en el cuento. En Bacantes, Penteo anhela ver las prácticas de las ménades lo que le acarrea -como lo señala el epígrafe de este apartado- su propia muerte. El narrador de "Las ménades" también destaca su pulsión de ver: "Es muy curioso pero yo no tenía ningún deseo de 
contribuir a esas demostraciones, solamente estar al lado y ver lo que ocurría, sobrepasado por ese homenaje inaudito" (Cortázar, 1996b, p. 327-328).

Según nuestro humilde parecer, la intertextualidad más importante yace en recuperar el núcleo de la presencia báquica en la tragedia de Eurípides:

La mayor de las locuras (al principio de la tragedia, Tiresias y Cadmo no dejan de tratar a Penteo como a un loco furioso) consistía en querer una ciudad perfectamente razonable y no dar cabida a lo irracional, a lo inesperado (v. 1391), a las fuerzas salvajes, a la parte inquietante de femineidad que necesariamente debe habitar la ciudad si se quiere que sea fecunda; es decir, en no dar cabida, en definitiva, a las manifestaciones imprevisibles de lo sagrado tanto como a sus manifestaciones cotidianas.

(Detienne, 1997, p. 285)

Dioniso también se define por ser la "irrupción de lo divino en el corazón de lo cotidiano" (Detienne, 1997, p. 285). Resulta ser, por lo tanto, una traducción de la propia estética de Cortázar. La dicotomía entre pensamiento mágico-mítico y racionalismo se traduce en la polarización nietzscheana entre lo apolíneo y lo dionisíaco. Más que una elección entre estos dos polos (Goyalde Palacios, 2001, p. 40), consideramos que estas categorías son elegidas por el escritor para señalar, por una parte, la repetición propia de la cultura occidental y, por otra, la raigambre antigua de su propia cosmovisión. Hemos considerado la presencia de lo báquico y hemos emparentado (como lo hace Ovidio) a Orfeo con Apolo, pero hay, incluso, otra vertiente a partir de la cual se manifiesta Apolo (Otto, 2003, p. 79): el racionalismo excesivo (“a lo entomólogo”) ${ }^{26}$ del narrador que constantemente exhibe su alta cultura y cosmopolitismo a partir de vocablos franceses y referencias como "el teatro de Florencia" (Cortázar, 1996b, p. 323). Como hemos establecido anteriormente, los mitos son "símbolos" (Cortázar, 2004a, p. 52) por lo que en este cuento el Maestro-Orfeo simboliza la alta cultura representada por la música clásica y el narrador-A polo, el racionalismo excesivo que rige a Occidente: "O sea que Occidente sigue su tradición helénica de racionalismo, Apolo gana hoy este round de su lucha secular con Dionisos" (Cortázar-Barrenechea, 1983, pp. 149-150).

Una vuelta de tuerca nos devuelve, también, una lectura metadiscursiva (Sosa, 2005) propia de Final del juego -que también señalábamos en Bestiario-y es que, además de proyectar la preferencia por lo dionisíaco, el cuento plantearía también, a través del mitema de la omofagia, ${ }^{27}$ una nueva metáfora del modo de apropiación hispanoamericana (representada por la localidad provinciana en que se sitúa el cuento) de la alta cultura europea (figurada por la música clásica):

El objetivo del autor es asimilar a las características de un ritual el fenómeno cultural y social que le era contemporáneo y pronunciarse, a través de la metáfora, transformando a su país en un escenario al que tumultuosamente accedían sus compatriotas para consumar el rito omofágico de devoradores de una cultura que los poseía. (González de Tobia, 1998, p. 97)

\section{"El Ídolo de las Cí́cladas"}

La estatuilla egea de la civilización cicládica (González de Tobia, 1998, p. 97), "Haghesa" (diosa del período preclásico), cierra el ciclo de cuentos en que lo femenino es intermediario entre el sujeto y la otredad (que definimos anteriormente como causalidad mítico-mágica), propio del surrealismo y presente en los tres cuentos. En "El ídolo de las Cícladas", lo femenino se manifiesta a través de la divinidad: "Es tan sencillo -dijo Somoza-. Siempre sentí que la piel estaba todavía en contacto con lo otro” (Cortázar, 1996b, p. 337). En los cuentos anteriores se trata de mujeres posesas ("ménades”) o una curandera del siglo XX ("Circe").

"El ídolo de las Cícladas" también conforma Final del juego y se emplaza en esta última línea que hemos mencionado, es decir, en el modo de apropiación de la tradición de parte del latinoamericano. ${ }^{28} \mathrm{El}$ relato se instala nuevamente en la antinomia racionalismo/pensamiento mágico y mítico; el primero representado por el personaje masculino europeo (francés), Morand, y el segundo por el sudamericano, Somoza. En sus Clases de Literatura, Cortázar se refiere a esta dicotomía en los siguientes términos: "Por supuesto Morand 
no le cree, con una mentalidad típicamente europea racionaliza lo que está escuchando y piensa que Somoza está loco" (2013, pp. 77-78).

Nuevamente, entonces, como en "Las ménades", la causalidad mágico-mítica ingresa a partir de la mania, de la locura (Dodds, 1997, p. 71): "Morand se sobresaltó como si regresara bruscamente de muy lejos. Recordó que antes de perderse en un vago fantaseo, había pensado que Somoza se estaba volviendo loco" (Cortázar, 1996b, p. 333).

Desde el inicio del cuento se plantea la dicotomía entre racionalismo y lo mágico-mítico. Las aristas que se desprenden de ella son tres: la antinomia entre intelectualidad e imaginación o sensatez y locura; la antinomia entre mentalidad europea y latinoamericana (específicamente francesa y rioplatense) y, finalmente, una pretendida superioridad de la cultura europea (diseñada por sus propios actores). De esta última vertiente va a surgir otra antítesis entre traducción e inefabilidad o cultura y vida.

La primera instancia se manifiesta a través de una tendencia constante a explicar y a comprender intelectualmente lo que sucede, instancia que se opone a la imaginación; la antinomia entre ambas facultades (intelecto e imaginación) se adjudica, además, a la cultura que utiliza cada una de ellas:

Somoza le confiaba su insensata esperanza de llegar alguna vez hasta la estatuilla por otras vías que las manos y los ojos y la ciencia, mientras el vino y el tabaco se mezclaban al diálogo con los grillos y el agua del torrente hasta no dejar más que una confusa sensación de no poder entenderse. Más tarde, cuando Somoza se fue a su tienda llevándose la estatuilla y Thérèse se cansó de estar sola y vino a acostarse, Morand le habló de las ilusiones de Somoza y los dos se preguntaron con amable ironía parisiense si toda la gente del Rio de la Plata tendria la imaginación fácil. (Cortázar, 1996b, p. 334) [La cursiva es nuestra]

La distinción entre mentalidad europea y mentalidad rioplatense se sostiene además por un atisbo de superioridad en la primera presente en la "ironía parisiense" de la cita anterior. El mismo Cortázar vuelve a este cuento en las Clases de literatura: Berkeley, 1980 sin dejar posibles malentendidos con respecto a la lectura que desea que se realice:

El hecho de que uno de los personajes fuera francés y el otro latinoamericano tenía su importancia en la medida en que el francés ve todo lo que sucede desde el punto de vista de una civilización racional que todo puede y quiere explicarlo: alucinación, locura, fantasía. En cambio Somoza, que es el hombre que irracionalmente ha creído posible entablar un contacto con un mundo arcaico y salvaje donde los sacrificios a los dioses son perpetuos como en tantas otras civilizaciones, afirma haber llegado allí y Morand no le cree. (Cortázar, 2013, p. 81) ${ }^{29}$

De esta antítesis se desprende otra oposición que da cuenta del modo de perpetrar o construir el conocimiento o el sentido: a partir de intentar buscar una explicación, Morand tratará de traducir los anhelos de Somoza, sin éxito:

Vista desde Morand la obsesión de Somoza era analizable: todo arqueólogo se identifica en algún sentido con el pasado que explora y saca a la luz. De ahí a creer que la intimidad con una de esas huellas podía enajenar, alterar el tiempo y el espacio, abrir una fisura por donde acceder a... Somoza no empleaba jamás ese vocabulario; lo que decía era siempre más o menos que eso, una suerte de lenguaje que aludía y conjuraba desde planos irreductibles. Ya por entonces había empezado a trabajar torpemente en las réplicas de la estatuilla; Morand alcanzó a ver la primera antes de que Somoza se fuera de París, y escuchó con amistosa cortesía los obstinados lugares comunes sobre la reiteración de los gestos y las situaciones como vía de abolición, la seguridad de Somoza de que su obstinado acercamiento llegaría a identificarlo con la estructura inicial, en una superposición que sería más que eso porque ya no habría dualidad sino fusión, contacto primordial (no eran sus palabras, pero de alguna manera tenía que traducirlas Morand cuando, más tarde, las reconstruía para Thérèse). (Cortázar, 1996b, p. 335) [La cursiva es nuestra]

La cita exhibe claramente, en primer lugar, la perspectiva ("vista desde Morand") racionalista ("análisis") del arqueólogo francés, así como su sentimiento de superioridad ("torpemente”) que se evidencia, por cierto, en que uno es sujeto y construye el conocimiento (Morand) y el otro se cosifica, se convierte en objeto de estudio, de análisis. Ello se enfatiza también desde lo tópico cuando se señala que Somoza se ha ido de París a los suburbios, es decir, hay un desplazamiento del centro (de la civilización) a los márgenes. En segundo lugar, se subraya la inefabilidad de la experiencia de Somoza ${ }^{30}$ en vínculo con las réplicas de la 
estatuilla. Esta operación (hacer réplicas o copias de la estatuilla, pero también responder oponiéndose a un mandato) remite a una inflexión metadiscursiva y está emparentada a la mímesis o modo de representación. En ella encontramos un paralelo de la reescritura y resemantización de los mitos griegos que realiza el propio Cortázar. Este cuento puede ser leído justamente como una metodología de incorporación de la cultura griega desde el orbe latinoamericano, pues a la apropiación del universo griego se le adosa una experiencia de lo sobrenatural enlazada al anhelo de Cortázar de unir arte y vida (Juárez, 2002, pp. 18-19).

$\mathrm{El}$ arte concebido no solo como réplica sino también como experiencia de lo sobrenatural abre otro esquema de oposiciones: tener una experiencia viva del arte o, en otras palabras, de la cosmovisión mágicomítica de la herencia grecolatina (de la que la estatuilla sería el pasaje) se opone a la codicia con que inicia el relato acoplada al arte como museo o colección:

Morand estuvo de acuerdo en que Somoza guardara por un tiempo la estatuilla. Era imposible venderla antes de un par de años; Marcos, el hombre que conocía a un coronel que conocía a un aduanero ateniense, había impuesto el plazo como condición complementaria del soborno. (Cortázar, 1996b, p. 335)

La experiencia de lo sobrenatural se vincula, incluso, con otra operación, "desandar" en línea con desarmar o deconstruir los saberes adquiridos por "los descendientes de los egeos", es decir, los europeos: "Pero había que desandar cinco mil años de caminos equivocados. Curioso que ellos mismos, los descendientes de los egeos, fueran culpables de ese error" (Cortázar, 1996b, p. 337). Y a partir de allí se indica el tacto como sentido de acceso a la otredad. Este modo de acceso y reactualización del pasado se opone a la metodología académica de Morand enlazada a lo fragmentario ("pegando minuciosamente los ínfimos trozos") e incompleto (en contraste con la plenitud que experimenta Somoza) sumado a la frustración de no comprender, de no poder recomponer el hilo del sentido (del significado) y permanecer en el ámbito de lo "inconcebible", de la indefinición:

\begin{abstract}
Morand maldijo en silencio esa mania sistemática de recomponer la vida como restauraba un vaso griego en el museo, pegando minuciosamente los ífimos trozos, y la voz de Somoza ahí mezclada con el ir y venir de sus manos que también parecían querer pegar trozos de aire, armar un vaso transparente, sus manos que señalaban la estatuilla, obligando a Morand a mirar una vez más contra su voluntad ese blanco cuerpo lunar de insecto anterior a toda historia, trabajado en circunstancias inconcebibles por alguien inconcebiblemente remoto, a miles de años pero todavía más atrás, en una lejanía vertiginosa de grito animal, de salto, de ritos vegetales alternando con mareas y sicigias y épocas de celo y torpes ceremonias de propiciación, el rostro inexpresivo donde solo la línea de la nariz quebraba su espejo ciego de insoportable tensión, los senos apenas definidos, el triángulo sexual y los brazos ceñidos al vientre, el ídolo de los orígenes, del primer terror bajo los ritos del tiempo sagrado, del hacha de piedra de las inmolaciones en los altares de las colinas. (Cortázar, 1996b, pp. 336-337) [La cursiva es nuestra]
\end{abstract}

\title{
A MODO DE CONCLUSIÓN
}

"El ídolo de las Cícladas" abre las puertas a otras mitologías presentes en la tercera sección del contario a través de "Axolotl" y "La noche boca arriba". Esta operación obedece a dos significaciones fundamentales, por una parte, el pensamiento mágico y mítico ha ingresado a partir de la alta cultura griega clásica dando cuenta de su prestigio y encuentra un punto de inflexión en la cultura cicládica (poco difundida y marginada del canon); a partir de allí, van a ingresar las culturas precolombinas también enlazadas a este tipo de mentalidad que se emplazan a la altura de la cultura clásica. Finalmente, la presencia de la cultura azteca en estos cuentos resemantiza y reescribe un sesgo propio de las vanguardias históricas que, en la búsqueda de otras maneras de ver el mundo, recuperan las culturas denominadas primitivas (principalmente africanas) [González Echevarría, 1974] haciéndose eco de esta operación, el latinoamericano mirará a su propia cultura y allí encontrará el universo precolombino pleno en riqueza y listo para reaparecer.

La tradición clásica aparece cobijada por un universo cifrado en los cuentos que hemos analizado cuya implicación principal se vincula con un discurso metapoético. La primera faceta se relaciona con la imagen del tapiz que remite a la técnica del collage, propia de la primera vanguardia, entendido como "una yuxtaposición 
de voces, sintagmas o discursos heterogéneos en los cuentos y novelas" (Romano, 2017, p. 58). El universo griego clásico forma parte de ese gran entramado heredado de la cultura europea que se presenta como una "maraña" o madeja enredada de la cual, el escritor, entreteje su estética. A esta metáfora se va a sumar la de la omofagía que retoma el modo de apropiación con que el latinoamericano fagocita la cultura europea, es decir, desanda la construcción racional de la realidad para retomar, de esa gran herencia griega, la mentalidad mítico-mágica.

La presencia de la tradición, entonces, implica tanto en "Circe" como en "Las ménades", la concepción del mito como un pasaje hacia esa mentalidad. "El ídolo de las Cícladas” le otorga sustento a la elección de la causalidad mágico-mítica al recuperar un período griego anterior al clásico que se vincula constantemente en el relato a la denominada (por la bibliografía antropológica que leía Cortázar) "mentalidad primitiva"; el cuento no se forja desde el esquema mítico, sino desde la valoración cultural de la herencia griega: Morand y Somoza representan las dos facetas del pensamiento del hombre occidental; para poder ingresar a la experiencia de lo sobrenatural es necesario dejar atrás ("sacrificar") la racionalidad excesiva en que ha caído Occidente y ponderar la mentalidad sobrenatural o mítico-mágica, representada por Somoza.

\section{ReFERENCIAS}

Álvarez, C. e Iglesias, R. M. (Eds. y Trads.). (1995). Ovidio: Metamorfosis. Madrid: Cátedra.

Avellaneda, A. (1983). Cortázar. Los años de Bestiario. En El habla de la ideología. Modos de réplica literaria en la Argentina contemporánea (pp. 93-127). Buenos Aires: Sudamericana.

Balderston, D. (1997). Borges: el escritor argentino y la tradición occidental. Cuadernos Americanos, 64, 167-178.

Balderston, D. (2013). Detalles circunstanciales: sobre dos borradores de "El escritor argentino y la tradición". Cuadernos Lírico [en línea], 9. doi: https://10.4000/lirico.1111

Borges, J. L. (2007). El escritor argentino y la tradición [1953]. En: Discusión. Obras completas I (pp. 316-324). Buenos Aires: Emecé.

Bornay, E. (2004). Las hijas de Lilith (5a ed.). Madrid: Cátedra.

Calvo, J. L. (Ed. y Trad.). (1994). Homero: Odisea. Barcelona: Altaya.

Castro-Klarén, S. (1980). Julio Cortázar, lector. Conversación con Julio Cortázar. Cuadernos Hispanoamericanos. Revista mensual de cultura hispánica, 364-366, Madrid, octubre-diciembre, 11-36.

Chartier, R. (1991). El mundo como representación. Estudios sobre historia cultural. (Trad. C. Ferrari). Barcelona: Gedisa.

Chazarreta, D. E. (2012). Lecturas de la tradición en la poesía de José Lezama Lima. Quilmes: Caligrafías. Recuperado de http://www.memoria.fahce.unlp.edu.ar/library?a=d\&c=libros\&d=Jpm461

Chazarreta, D. E. (2017). Tradición clásica en El arco y la lira de Octavio Paz. El hilo de la fábula, 16, 95-108. Recuperado de: https://bibliotecavirtual.unl.edu.ar/publicaciones/index.php/HilodelaFabula/article/view/62 84

Chiampi, I. (1985). La expresión americana de José Lezama Lima: la dificultad y el diabolismo del caníbal. Escritura, $X$, enero-diciembre, 19-20.

Contreras, S. (1993). Variaciones sobre el escritor argentino y la tradición. Paradoxa. Literatura y Filosofía, 7, 38-51.

Cortázar, J. (1996a). Bestiario. En Cuentos completos/1. Buenos Aires: Alfaguara.

Cortázar, J. (1996b). Final del juego. En Cuentos completos/1. Buenos Aires: Alfaguara.

Cortázar, J. (2004a). La urna griega en la poesía de Keats. En Obra crítica/2 (pp. 31-99). Edición de Jaime Alazraki. Buenos Aires: Suma de Letras Argentina.

Cortázar, J. (2004b). Para una poética. En Obra crítica/2 (pp. 361-390). Edición de Jaime Alazraki. Buenos Aires: Suma de Letras Argentina.

Cortázar, J. (2013). Clases de Literatura. Berkeley, 1980. Buenos Aires: Alfaguara. 
Cortázar, J. y Barrenechea, A. M. (1983). Cuaderno de bitácora de "Rayuela". Buenos Aires: Sudamericana.

Darmon, J. (1997). Dioniso II. La fiesta, el teatro, los misterios. En Y. Bonnefoy (Dir.), J. Pòrtulas (Ed.) y M. Solana (Ed. y Trad.), Diccionario de las mitologias (2a ed.): Vol. II. Grecia (pp. 281-292). Barcelona: Destino.

Detienne, M. (1997). Dioniso I. El extranjero en la ciudad. En Y. Bonnefoy (Dir.), J. Pòrtulas (Ed.) y M.Solana (Ed. y Trad.) Diccionario de las mitologías (2a ed.): Vol. II: Grecia (pp. 275-281). Barcelona: Destino.

Díez del Corral, L. (1974). La función del mito clásico en la literatura contemporánea (2a ed.). Madrid: Gredos.

Dodds, E. (1997). Los griegos y lo irracional (Trad. M. Araujo). Madrid: Alianza.

Dodds, E. (Ed.). (1960). Euripides: Bacchae (2a ed.). Oxford: Oxford University Press.

Eurípides. (1998). Bacantes. Edición bilingüe (Trad. C. García Gual). Madrid: Gredos.

García Canclini, N. (1968). Cortázar. Una antropología poética. Buenos Aires: Nova.

Goloboff, M. (1998). Julio Cortázar. La biografía. Buenos Aires: Seix Barral.

González de Tobia, A. (1998). Julio Cortázar y el mito griego. Vinculación y contraste con algunos tratamientos de Borges y Marechal. Synthesis, 5, 85-113.

González Echevarría, R. (1974). Isla a su vuelo fugitiva: Alejo Carpentier y el realismo mágico. Revista Iberoamericana, $X L(86)$, Pittsburgh, enero-marzo, 9-63.

Goyalde Palacios, P. (2001). "Las Ménades" de Julio Cortázar: mito clásico y recreación literaria. Faventia, 23(2), 35-42. Recuperado de: http://ddd.uab.es/pub/faventia/02107570v23n2p35.pdf

Hernández del Castillo, A. (2005). Woman as Circe the Magician. En H. Bloom (Ed.), Julio Cortázar (pp. 71-100). Filadelfia: Chelsea House.

Highet, G. (2015). The Classical Tradition. Greek and Roman Influences on Western Literature (s/ed.). With a new foreword by Harold Bloom (Trabajo original publicado en 1949). New York: Oxford University Press.

Homer. (1945). Odyssey (Trad. A. T. Murray). Cambridge-London: Harvard University Press.

Juárez, L. (2002). Tradición y ruptura: apuntes sobre el repertorio mítico en algunos relatos de Julio Cortázar. En M. Goloboff (Comp.), Julio Cortázar y el relato fantástico (pp. 15-29). La Plata: Facultad de Humanidades de la Universidad Nacional de La Plata.

Lafaye, G. (Ed. y Trad.). (1957). Ovide: Les Metamorphoses. Paris: Belles Lettres.

Lévi-Strauss, C. (1969). Magia y religión. En Autor (Ed.), Antropología estructural (2ª ed. Trad. E. Verón, pp. 151-167). Buenos Aires: EUDEBA.

Lezama Lima, J. (2013). Julián del Casal [1941]. Prólogo y notas de A. Cruz-Malavé. La Habana Elegante, SpringSummer. Recuperado de http://www.habanaelegante.com/Spring_Summer_2013/Hojas_CruzMalave.html

Maturo, G. (2014). Julio Cortázar. Razón y revelación. CABA: Biblos.

Meyer-Minneman, K. y Luengo, A. (2004). (Des)enmascaramientos de "Las Ménades" y "La escuela de la noche" de Julio Cortázar. Hispamérica, 98, 31-99.

Otto, W. (2003). Los dioses de Grecia (Trad. R. Berge y A. Murguía Zurriarían). Madrid: Siruela.

Pierrot, J. (1977). L’imaginaire décadent (1880-1900). París: Université de Paris.

Real Academia Española. (2014). Diccionario de la lengua española (23a ed.). Recuperado de https://dle.rae.es/

Romano, E. (2017). Cortázar, 1963. Acerca de Rayuela. CABA: UNIPE.

Sosa, C. H. (2005). Juego, arte y autorreflexión. Otra vuelta de tuerca a «Final del juego» de Julio Cortázar. Alba de América, 24(45-46), Westminster, Instituto Literario y Cultura Hispánico, California State University, 39-52.

Taylor, M. (1973). Los Reyes de Julio Cortázar: El Minotauro Redimido. Revista Iberoamericana, XXXIX(84-85),

\section{Notas}

* Daniela E. Chazarreta es Investigadora Adjunta del Consejo Nacional de Investigaciones Científicas y Técnicas (CONICET) y Profesora a cargo de Literatura Latinoamericana para Lenguas Modernas en la Universidad Nacional 
de La Plata (Argentina). Sus líneas de investigación han sido la poética del espacio en el modernismo hispanoamericano, en José Lezama Lima, en César Dávila Andrade y en Vicente Gerbasi; la tradición clásica, la construcción de la tradición y las relaciones entre artes visuales y literatura hispanoamericana. Su proyecto actual es la poética del espacio en Octavio Paz (1958-1968). Ha obtenido su Doctorado en Letras en la mencionada universidad y becas de investigación otorgadas por esta institución y el CONICET. Entre sus publicaciones se destacan los libros Lecturas de la tradición en la poesía de José Lezama Lima (2012) y Tramas del linaje en "Muerte de Narciso" de José Lezama Lima (2012). Dirige el Proyecto de Investigación y Desarrollo (PID H878) "Paisaje y modernidad en la literatura hispanoamericana (1845-1993)", financiado por la UNLP.

1 Dejamos a un lado Los reyes (1949), pues consideramos (coincidiendo con Graciela Maturo) que corresponde a una primera época estética de Cortázar (Maturo, 2013, pp. 32-35). Existen muchos análisis del texto: pueden consultarse González de Tobia (1998, pp. 90-93) y Taylor (1973).

2 Rubén Darío lo realiza en "Los colores del estandarte" (1896) y Jorge Luis Borges en "El escritor argentino y la tradición” (1953); José Lezama Lima lo hará en muchos ensayos e incluso en su poesía, pero destacamos sobre todo "Julián del Casal" (1941). Para un estudio pormenorizado del ensayo de Borges puede revisarse Balderston (1997) y (2013), Contreras (1993). Hemos analizado estos temas en el artículo "Tradición clásica en El arco y la lira de Octavio Paz" (2017) y también en Lecturas de la tradición en la poesía de José Lezama Lima (2012). De modo de poner en relevancia el marco teórico desde el cual analizamos el corpus cortazariano seleccionado, realizamos una breve síntesis revisada de lo allí mencionado sobre la categoría de tradición clásica y su adecuación o justeza en el universo hispanoamericano.

3 Para una exhaustiva descripción de la biografía de Cortázar se puede consultar Goloboff (1998), Maturo (2014, pp. 15-24) y Romano (2018, pp. 13-29).

4 Así lo refiere Cortázar en "Para una poética" (1954): "Los hechos son simples: en cierto modo el lenguaje íntegro es metafórico, refrendando la tendencia humana a la concepción analógica del mundo y el ingreso (poético o no) de las analogías en las formas del lenguaje. Esa urgencia de aprehensión por analogía, de vinculación pre-científica, naciendo en el hombre desde sus primeras operaciones sensibles e intelectuales, es la que lleva a sospechar una fuerza, una dirección de su ser hacia la concepción simpática, mucho más importante y trascendente de lo que todo racionalismo quiere admitir. Esa dirección analógica del hombre, superada poco a poco por el predominio de la versión racional del mundo, que en el Occidente determina la historia y el destino de las culturas, persiste en distintos estratos y con distintos grados de intensidad en todo individuo" (2004b, p. 365).

5 Citamos de la edición y traducción de Calvo (1994). Hemos consultado también la traducción de Murray de 1945.

6 Tanto Graciela Maturo (2014, p. 29) como Eduardo Romano (2017, p. 33) y Ana Hernández del Castillo (2005) insisten en la filiación de Cortázar con las poéticas de la modernidad (John Keats, por supuesto, Charles Baudelaire, Stephan Mallarmé, Guillaume Apollinaire, el surrealismo, entre otros). Estos autores, con los que coincidimos, señalan que esta etapa -en la que nuestro corpus está incluido- es predominantemente esteticista; la impronta se proyecta en el repliegue que implica la constante reflexión sobre la propia poética también presente en sus primeros cuentos (tal y como lo estamos planteando en el artículo). Si bien, como ha analizado Andrés Avellaneda (1983) existen atisbos que llevan al cifrado del contexto sociopolítico, no podríamos incluir a este cuento en lo que se denomina literatura comprometida. Para una lectura en esta última línea referida puede consultarse Meyer-Minneman y Luengo (2004).

7 En su ensayo "Para una poética" (1954), cercano tanto a Bestiario (1951) como a Final del juego (1956), Cortázar define de esta manera la relación entre hombre y aprehensión del mundo (transcribimos parte de una de las citas anteriormente realizadas): "Esa dirección analógica del hombre, superada poco a poco por el predominio de la versión racional del mundo, que en el Occidente determina la historia y el destino de las culturas, persiste en distintos estratos y con distintos grados de intensidad en todo individuo" (2004b, p. 365).

8 Las variables temporales corresponden a la mención de la pelea Firpo-Dempsey que se concretó el 14 de septiembre de 1923 y las variables espaciales, a las calles de la ciudad de Buenos Aires de aquel momento, en especial a los barrios de Almagro y Once.

9 Todas las citas se harán de esta edición.

10 Posteriormente nos encontramos con la siguiente referencia: "Sin darse cuenta, Mario juntaba pedazos de episodios, se descubría urdiendo explicaciones paralelas al ataque de los vecinos” (Cortázar 1996a, p. 146).

11 Otra definición interesante en nuestra línea de lectura es "conjunto de hebras bastas, enredadas, y de grueso desigual, en la parte exterior de los capullos de seda, que se apartan al hacer el hilado, y se emplean en tejidos de inferior calidad" (Real Academia Española, 2014, 23a ed.).

12 En una entrevista con Sara Castro-Klarén, Cortázar se refiere a la importancia del pensamiento de Claude Lévi-Strauss (Bruselas, 1908-París, 2009) y Lucien Lévi-Bruhl (París, 1857-1939): "En realidad yo pasé de la filosofía pura que leía en la Argentina: Aristóteles, Platón, Kant, pasé, digamos, a la antropología, un poco a través de Cassirer, a quien leí enormemente en mis últimos años de la Argentina y que me influyó mucho. Y luego la antropología en la línea de LévyBruhl y luego, más tarde, Lévi-Strauss. Yo pienso que ese tipo de antropología me mostró una serie de dimensiones que 
funcionaban dentro de la órbita de mis intereses literarios, que eran al mismo tiempo y son mis intereses de tipo vital. Esa nueva concepción de la mentalidad primitiva con todas las diferencias que hay entre los dos Lévi me fascinó y me fascina, porque la lectura de esos estudios amplifica enormemente la concepción cotidiana de la inteligencia humana, de la conducta humana, de la relación del hombre con su universo" (Castro-Klarén, 1980, p. 26).

13 En Odisea 10.231 se menciona "la hermosa voz" de Circe; Delia toca el piano a media luz cada vez que Mario va a visitarla y una vez que sus padres se van a dormir: "Agitando los periódicos volvieron a su cuarto, y Mario se quedó con Delia y el piano, con Delia y la llamada de amor indio” (Cortázar, 1996a, p. 151).

14 Cf. Bornay, 2004, p. 16.

15 Obras plásticas que ejemplifican esta mirada fin de siècle sobre lo femenino son Circe (1893) de Arthur Hacker y Circe Poisoning the Sea [Circe envenenando el mar] (1892) de John Waterhouse.

16 Las citas de Bacantes de Eurípides se harán de la traducción de García Gual de 1998. También hemos consultado Dodds (1960).

17 Cf. Darmon, 1997; Dodds, 1997.

18 Leemos en el relato cortazariano: "El Maestro entraba y salía, con su destreza elegante y su manera de subir al podio como quien va a abrir un remate" (1996b, p. 324); posteriormente se enfatiza esta idea desde otro matiz: "De toda esa gente, los músicos y el Maestro parecían los únicos dignos” (1996b, p. 325). Es muy sugestivo, además, el parecido de la referencia a los gestos propios del trance báquico entre el texto de Cortázar y el de Dodds: "Y vemos esta cabeza echada violentamente hacia atrás y esta garganta vuelta hacia arriba en antiguas obras de arte, como las gemas que reproduce Sandys [...] o la ménade del bajorrelieve del Museo Británico [...]” (Dodds, 1997, p. 255). No podemos afirmar que Cortázar haya leído este clásico de la cultura griega, pero, por otra parte, el texto es originalmente de 1951. Nos consta (no solo a nosotros, sino que emerge de sus estudios sobre Keats) el amplio conocimiento que Cortázar tenía de los clásicos; además del lazo que lo unía a Arturo Marasso (a quien dedica su artículo sobre Keats), gran estudioso del universo grecolatino en nuestro país.

19 Cf., por ejemplo, la siguiente cita: "Me pareció curiosa esa sustitución progresiva de la luz por el ruido, y cómo uno de mis sentidos entraba en juego justamente cuando el otro se daba al descanso" (Cortázar, 1996b, p. 323).

20 Erwin Dodds, en The Greeks and The Irrational, menciona "tímpanos o timbales que acompañan la danza de las ménades en las Bacantes y en los vasos griegos" (1997, p. 254).

21 Anteriormente se hace referencia a los instrumentos de percusión y a los gritos propios del trance báquico: “ $i V e n i d$ bacantes! ¡Venid bacantes! Con la suntuosidad del Tmolo de áureas corrientes cantad a Dioniso, al son de los panderos de sordo retumbo, festejando con gritos de ¡evohé! al dios del evohé, entre los gritos y aclamaciones frigias, al tiempo que la sagrada flauta de loto melodiosa modula sus sagradas tonadas, en acompañamiento para las que acuden al monte, al monte. Alborozada entonces, como la potranca junto a su madre en el prado, avanza su pierna de raudo paso en brincos la bacante" (vv. 155-165).

22 El término entusiasmo se repite siete veces desde el principio hasta el final del cuento encontrando ecos semánticos que tratan de recuperar los matices de su par griego, enthusiasmós, traducido como arrebato, trasporte divino, inspiración divina, posesión divina: "furiosas"; “arrebatos"; “excitadísima”, “éxtasis de la tragedia”. Lejos de ocultarlos, el texto se encarga de enfatizar la presencia mítica a partir del nivel léxico.

23 Nos referimos a la caza animal tal como se señala en los relatos acerca de las bacantes; en el cuento leemos la siguiente referencia: "Algo como una mancha roja me obligó a mirar hacia el centro de la platea, y nuevamente vi a la señora que en el intervalo había corrido a aplaudir al pie del podio. Avanzaba lentamente, yo hubiera dicho que agazapada aunque su cuerpo se mantenía erecto, pero era más bien el tono de su marcha, un avance a pasos lentos, hipnóticos, como quien se prepara a dar un salto" (Cortázar, 1996b, p. 326).

24 Marcel Detienne, en su artículo sobre Dioniso, refiere lo siguiente: “Arrastrados por la cacería [...], los seguidores de Dioniso se convierten en salvajes y siguen una vía que les permite escapar de la condición humana evadiéndose de ella a través de la bestialidad y situándose al lado de los animales, siguiendo el ejemplo del dios nacido de una vaca y llamado Toro por sus fieles" (1996, p. 281).

25 Los ejemplos del uso de la disemia son "bestial" (de la cita anterior) y "brutal" (de una de las siguientes citas); ambos se utilizan tanto en su asociación a bestia o bruto (términos utilizados para referir los animales de carga) y también en su acepción de extraordinario o fantástico en línea con el sociolecto de la clase media a la que pertenecen los personajes.

26 Cf. Cortázar, 1996b, p. 320.

27 Un largo linaje de textos compone la imagen del latinoamericano como un voraz devorador de la cultura europea. Irlemar Chiampi lo expresa con claridad al mencionar que la marca diferencial de la cultura latinoamericana es su política transgresora de dominar la cultura del colonizador para asimilarlo y transmutarlo "en una espectacular operación antropofágica" (1985: 106).

28 Es el propio Cortázar el que utiliza el término "latinoamericano" en lugar de hispanoamericano, sobre todo en referencia a este cuento tal como lo mencionamos posteriormente. 
29 Recordamos que se trata, por cierto, de arqueólogos, es decir, de profesionales que sistematizan y explican el pasado de las civilizaciones a partir de restos materiales. Posteriormente, el texto insiste en la necesidad de explicar: "Por favor dijo Morand-, ¿ no podrías hacer el esfuerzo para explicarme aunque creas que nada de eso se puede explicar?” (Cortázar, 1996b, p. 337); antes del final del cuento, se enfatiza: "Levantó el vaso del suelo y bebió lo que quedaba de whisky, pensando que Thérèse llegaría de un momento a otro y que habría que hacer algo, avisar a la policía, explicarse" (Cortázar, 1996b, p. 338).

30 Hacia el inicio del texto Somoza menciona la imposibilidad de expresar con palabras su anhelo: "«No hay palabras para eso», acababa de decir Somoza. «Por lo menos nuestras palabras»” (Cortázar, 1996b, p. 334). 